\title{
Unique Hydrogen Adsorption Properties of Graphene
}

\author{
Lifeng Wang, Nicholas R. Stuckert, and Ralph T. Yang \\ Dept. of Chemical Engineering, University of Michigan, Ann Arbor, MI 48109
}

DOI 10.1002/aic.12470

Published online November 29, 2010 in Wiley Online Library (wileyonlinelibrary.com).

\begin{abstract}
Graphene showed an unusually high hydrogen storage capacity as well as a unique, slow hydrogen adsorption process compared with a variety of carbon materials (carbon nanotubes, activated carbons, mesoporous carbons, templated carbons, and metal organic frameworks). Catalytic dissociation of hydrogen on graphene is observed for the first time. The hydrogen dissociation rate on graphene is also significantly faster than the adsorption rate. This leads to the conclusion that the most active sites on graphene for hydrogen dissociation are not the only sites where the enhanced adsorption occurs. The mechanistic differences in adsorption on graphene when compared with the other carbons are further demonstrated by differences in temperature-programed desorption results and heats of adsorption. () 2010 American Institute of Chemical Engineers AIChE J, 57: 2902-2908, 2011
\end{abstract}

Keywords: absorption, materials, adsorption/gas, surface chemistry/physics, catalysis

\section{Introduction}

Since the first isolation of graphene from graphite, ${ }^{1}$ graphene has been synthesized by various routes ${ }^{2-5}$ and has shown a wide variety of fascinating properties, such as the quantum Hall effect at room temperature (RT), extremely high carrier mobility, ambipolar field effect, and sensitive response to single molecules. ${ }^{6,7}$ The recent theoretical calculation results indicate that graphene may also work as a sorbent for hydrogen storage. ${ }^{8-10}$ Various nanostructured and microporous carbon-based materials including carbon nanotubes (CNTs), activated carbons (ACs), mesoporous carbons (MCs), templated carbons (TCs), and metal organic frameworks (MOFs) have been studied intensively because of their light weight, high surface areas, and relative chemical stabilities. ${ }^{11-17}$ However, recent results showed that these carbonbased materials cannot store a sufficient amount of $\mathrm{H}_{2}$ required for transportation applications merely by physical adsorption at ambient temperature. Novel storage sorbent

\footnotetext{
Additional Supporting Information may be found in the online version of this article.

Correspondence concerning this article should be addressed to R. T. Yang at yang@umich.edu.

(C) 2010 American Institute of Chemical Engineers
}

materials and ways to further enhance the storage capacities need to be explored.

The promising results predicted for hydrogen storage on ideal graphene have stimulated experimental studies. ${ }^{8-10}$ However, experimental studies have been limited to hydrogen adsorption on low-surface-area graphene-like materials ${ }^{18-20}$ and the hydrogenation of supported graphene membrane by plasma exposure or the use of a hydrogen atom beam source. $^{21,22}$ An in-depth study of hydrogen adsorption on graphene and an understanding of the adsorption process are desired. In this work, we studied the hydrogen adsorption properties of graphene with a high surface area of $2139 \mathrm{~m}^{2} / \mathrm{g}$ and compared it with the most studied carbon materials (for $\mathrm{H}_{2}$ storage). Among all the tested carbons, graphene showed a superior hydrogen storage capacity as well as displaying a uniquely slow hydrogen adsorption process. We have also observed catalytic hydrogen dissociation on graphene for the first time and compared its similarities to metal-doped carbons.

\section{Experimental Synthesis}

The graphene was prepared by following a published solvothermal and sonication procedure. ${ }^{4}$ Typically, $2 \mathrm{~g}$ of sodium 
and $5 \mathrm{~mL}$ of ethanol (molar ratio, 1:1) were sealed in a teflon-lined reactor vessel and heated at $493 \mathrm{~K}$ for $72 \mathrm{~h}$. After that the reactor vessel was cooled to RT and a solid solvothermal product (graphene precursor) was obtained. This material was then transferred to a horizontal quartz tube in He atmosphere and rapidly pyrolyzed at $1323 \mathrm{~K}$ for $2 \mathrm{~min}$. The resulting black product was washed with copious amounts of deionized water and sonicated in ethanol. The final product was collected by filtration and dried in vacuo at $373 \mathrm{~K}$ for $24 \mathrm{~h}$.

Mesoporous carbon, templated carbon 1 (TC-1), templated carbon 2 (TC-2), templated carbon 3 (TC-3), and MOF-177 were prepared according to the published procedures. ${ }^{23-28}$ The superactivated carbons AX-21 and Maxsorb were obtained from Anderson Development Company and Tokyo Zairyo, respectively. CNT-1 was obtained from Shenzhen Nanotech Port. The storage capacity of CNT-2 was cited from previous literature. ${ }^{29}$ A total of $6 \mathrm{wt} \%$ Pt-doped $\mathrm{AX}-21$ was synthesized according to previous literature. ${ }^{30}$

\section{Characterization}

Nitrogen adsorption isotherms and low-pressure $\mathrm{H}_{2}$ adsorption isotherms (0-1 atm) were measured by using a Micromeritics ASAP 2020 Analyzer. Nitrogen adsorption isotherms were measured at $77 \mathrm{~K}$. Low-pressure $\mathrm{H}_{2}$ adsorption isotherms were measured at 273, 298, and $323 \mathrm{~K}$. Circulating baths were used to maintain the sample at 298 or $323 \mathrm{~K}$. An ice-water filled dewar flask was used to maintain $273 \mathrm{~K}$, and liquid nitrogen was used for $77 \mathrm{~K}$. High-resolution transmission electron microscopy (HRTEM) images of the materials were obtained on a JEOL 3011 analytical electron microscope equipped with EDX analysis operated at 300 $\mathrm{kV}$. The elemental ratio of graphene was approximately $\mathrm{C}$ : 93\%, O: $6.5 \%$, and Na: $0.5 \%$ as analyzed by a Kratos Axis ultra XPS spectrometer (Supporting Information Figure S1).

Hydrogen adsorption at $298 \mathrm{~K}$ and pressures greater than $0.1 \mathrm{MPa}$ and up to $10 \mathrm{MPa}$ was measured using a static volumetric technique with a specially designed Sieverts-type apparatus. The apparatus was previously tested and proved to be leak free and accurate through calibration by using $\mathrm{LaNi}_{5}, \mathrm{AX}-21$ carbon, zeolites, and MOFs at $298 \mathrm{~K}^{31} \mathrm{As}$ shown in our previous work, the high-pressure isotherms of the commercially available superactivated carbons (i.e., AX-21, GX-31, and Maxsorb) are known and have been used as standard materials for testing of the measurements. For a superactivated carbon with a BET surface area of 2800 $\mathrm{m}^{2} / \mathrm{g}$, the isotherm at $298 \mathrm{~K}$ should be slightly concave with an uptake of $0.6 \mathrm{wt} \%$ at $10 \mathrm{MPa}^{31}$ Approximately $200 \mathrm{mg}$ of sample was used for each high-pressure isotherm measurement. Analysis of evolved gases during TPD experiments was performed with an AeroVac 1200 Magnetic Sector mass spectrometer (VTI).

\section{$\mathrm{H}_{2} / \mathrm{D}_{2} / \mathrm{HD}$ isotope equilibrium reaction and temperature-programed desorption}

The $\mathrm{H}_{2} / \mathrm{D}_{2} / \mathrm{HD}$ equilibrium on graphene was measured using a slightly modified procedure proposed by Ishikawa et al. ${ }^{32}$ In this new procedure, $\mathrm{H}_{2}$ and $\mathrm{D}_{2}$ were mixed in a 1:1 ratio at 4.3 $\mathrm{MPa}$. This mixture was allowed to equilibrate for $2 \mathrm{~h}$ at RT before being exposed to the sample at 1.6

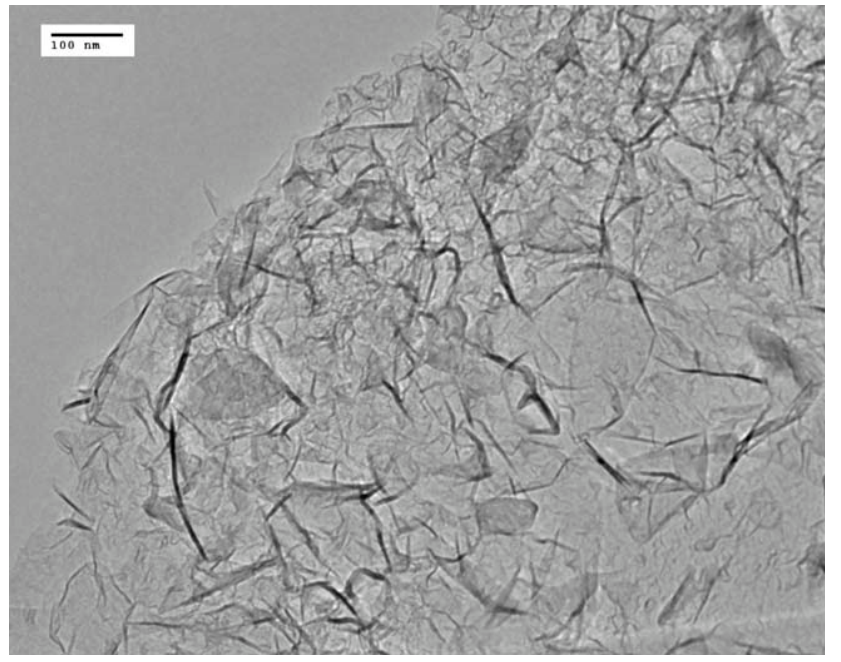

Figure 1. TEM image of graphene.

MPa. The small sample cell was then closed and allowed to react for a given amount of time before being quenched in liquid nitrogen. The gas in the sample cell was analyzed using mass spectrometer (MS) after 5 min from initial sample cell submersion in liquid nitrogen. The MS was set in sweep mode to analyze $(\mathrm{m} / \mathrm{z})$ peaks $1-6$ to fully differentiate hydrogen, deuterium hydride, and deuterium. Twenty-milligram samples of graphene, AX-21, and 6 wt \% Pt-doped AX-21 were subjected to this treatment for a series of different reaction times and compared to the results obtained using a blank sample cell. All samples were degassed at $523 \mathrm{~K}$ for $8 \mathrm{~h}$ under vacuum, except Pt-doped AX-21, which was degassed at $623 \mathrm{~K}$ and an annealed graphene degassed at $823 \mathrm{~K}$. A reaction rate constant was also obtained for the blank cell, which was made of stainless steel.

Temperature-programed desorption (TPD) was performed on the samples once all physisorbed hydrogen was removed (20 min) and the $\mathrm{m} / \mathrm{z} 2$ peak had fallen to baseline. Heating at $10 \mathrm{~K} / \mathrm{min}( \pm 1 \mathrm{~K} / \mathrm{min})$ was performed while analyzing $(\mathrm{m} / \mathrm{z})$ peaks $1-6$ to determine total hydrogen species desorbed.

\section{Results and Discussion}

The published solvothermal and sonication procedure ${ }^{4}$ was selected because the production of graphene can be in gramquantities, which is beneficial for achieving accurate storage measurements and for use in further applications. The TEM image of the products (Figure 1) clearly shows the wrinkled graphene sheets and overlap between different sheets, which are in agreement with previous literature. A $\mathrm{N}_{2}$ isotherm at $77 \mathrm{~K}$ on graphene showed an increase at a low relative pressure and a hysteresis loop at pressures from 40 to $100 \mathrm{kPa}$ (Supporting Information Figure S2). The graphene had a BET surface area of $2139 \mathrm{~m}^{2} / \mathrm{g}$, which was less than the $2630 \mathrm{~m}^{2} / \mathrm{g}$ for ideal single-layer graphene. This indicates some partial overlap of graphene sheets rather than completely separated single-layer graphene.

Hydrogen storage on graphene was investigated at $298 \mathrm{~K}$ and up to $10 \mathrm{MPa}$. As shown in Figure 2, graphene exhibited a surprisingly high storage capacity of $0.90 \mathrm{wt} \%$. The hydrogen storages of a series of carbon materials including 


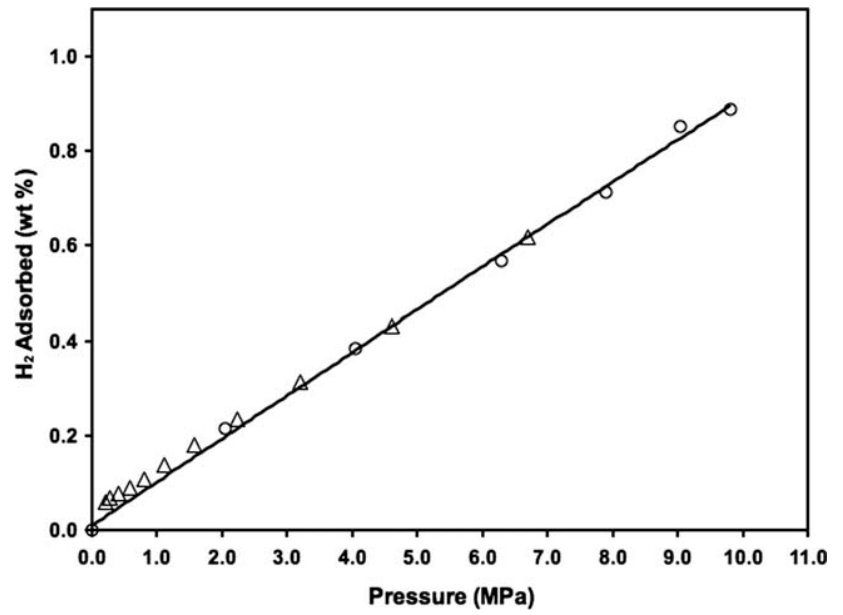

Figure 2. High-pressure hydrogen isotherms on graphene at $298 \mathrm{~K}$.

Adsorption $(\bigcirc)$ and desorption $(\Delta)$.

CNT, AC, MC, TC, and MOF were measured to compare with graphene. In Figure 3, there is a clear relationship between the storage capacity and the BET surface area for all other tested carbons (with surface areas ranging from 810 to $3840 \mathrm{~m}^{2} / \mathrm{g}$ ), as expected for physical adsorption. This correlation is in agreement with previous reports. ${ }^{11,13}$ However, the storage capacity of graphene was well above the correlation. The capacity of $0.90 \mathrm{wt} \%$ for graphene was the highest compared with all the other carbons $(0.62 \mathrm{wt} \%$ for AX-21, 0.72 wt $\%$ for Maxsorb, 0.66 wt $\%$ for MOF-177, and 0.82 wt $\%$ for TC-3). If we consider the correlation between the capacity and surface area and extrapolate linearly, a carbon with a BET surface area of $2139 \mathrm{~m}^{2} / \mathrm{g}$ should have a capacity of 0.56 wt $\%$ at $10 \mathrm{MPa}$. This showed that the storage capacity on graphene was enhanced by $60 \%$. The reversibility was assessed by measuring the desorption branch down to $1 \mathrm{~atm}$. It can be seen from Figure 2 that the desorption branch nearly coincided with the adsorption branch although there appeared to be a slight hysteresis. However,

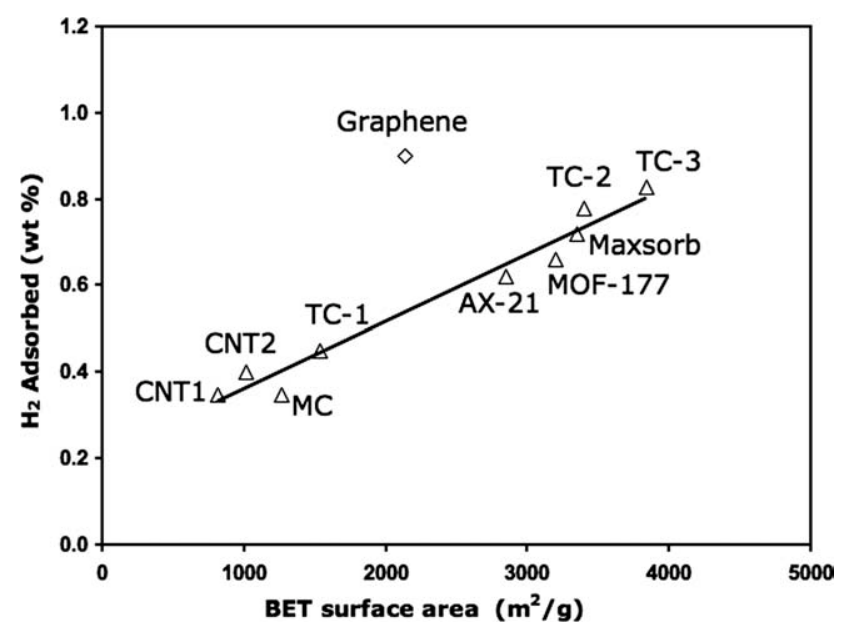

Figure 3. Relationship between the BET surface area of carbons and their storage capacities at $298 \mathrm{~K}$ and $10 \mathrm{MPa}$.

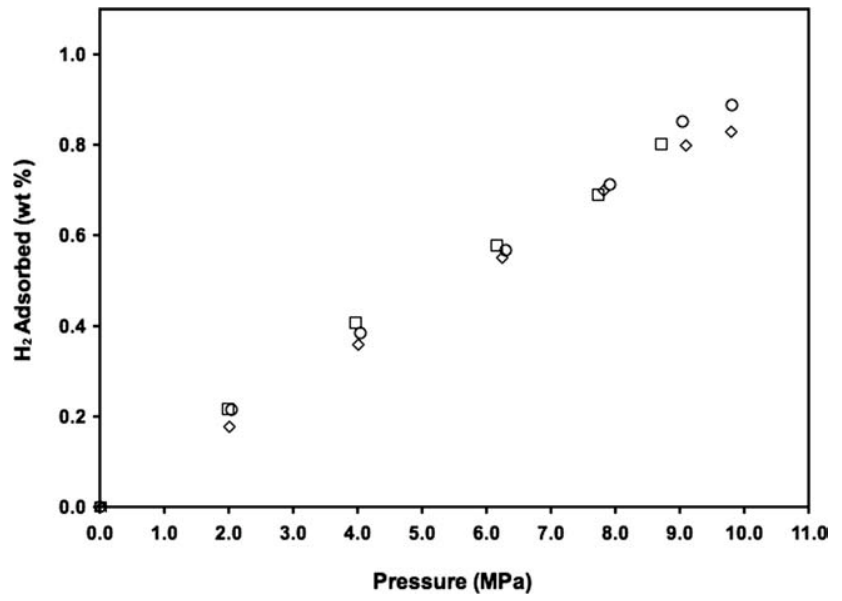

Figure 4. Three consecutive hydrogen adsorption isotherms on graphene in three adsorption-desorption cycles at $298 \mathrm{~K}$.

the next two adsorption branches were in agreement with the first adsorption branch indicating no observable loss in adsorption sites during adsorption-desorption cycles at 298 $\mathrm{K}$ (Figure 4).

To evaluate the interactions between graphene and $\mathrm{H}_{2}$, the isosteric heats of adsorption were calculated from the adsorption isotherms at different temperatures by using the Clausius-Clapeyron equation (Figure 5). The hydrogen adsorption isotherms were measured at 273,298 , and $323 \mathrm{~K}$, and the heat of adsorption values were determined using the slope of a plot of $\ln (P)$ vs. $(1 / T)$. The heats of adsorption were $\sim 12 \mathrm{~kJ} / \mathrm{mol}$ at low surface coverage and leveled off to $\sim 8 \mathrm{~kJ} / \mathrm{mol}$ at higher surface coverages. The high values of heat of adsorption at low surface coverage can be attributed to the adsorption of $\mathrm{H}_{2}$ on the more energetic sites on graphene. Defect sites and edge sites (i.e., armchair and zigzag edge sites) are strong sites for adsorption. The heat of adsorption $(\sim 8 \mathrm{~kJ} / \mathrm{mol})$ on graphene at high coverages is clearly higher than that of $\mathrm{H}_{2}$ on microporous carbons such as activated carbon $(\sim 5 \mathrm{~kJ} / \mathrm{mol}){ }^{33}$

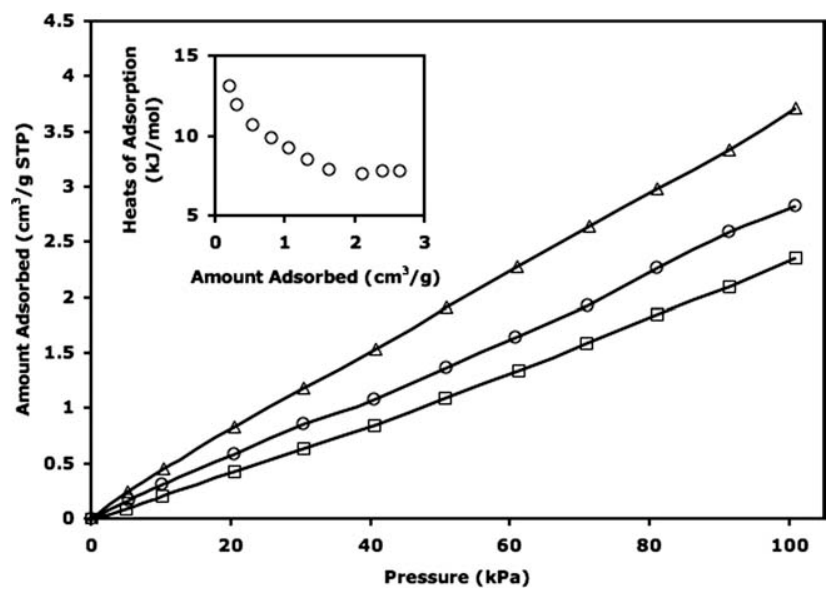

Figure 5. Hydrogen isotherms on graphene at $273 \mathrm{~K}$ $(\Delta), 298 \mathrm{~K}(\bigcirc)$, and $323 \mathrm{~K}(\square)$; heats of adsorption (inset).

October 2011 Vol. 57, No. 10

AIChE Journal 


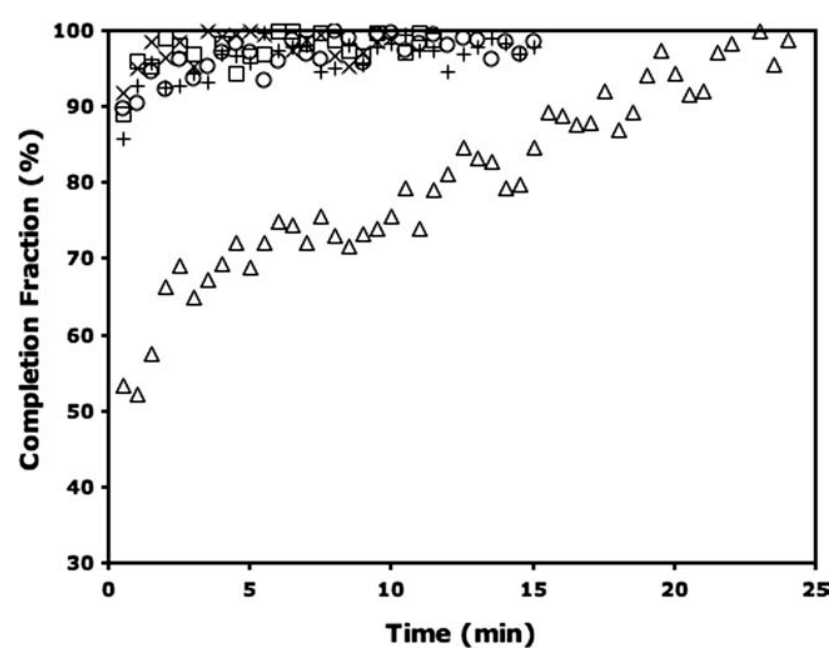

Figure 6. Fractional completion for hydrogen uptake at $298 \mathrm{~K}$ on AX-21 (x), Maxsorb (○), CNT ( $\square$ ), templated carbon $(+)$, and graphene $(\Delta)$ at $\sim 6$ $\mathrm{MPa}$ end pressure.

To understand the high capacity of graphene and the adsorption mechanism, we studied the adsorption kinetics on graphene and compared it with other carbons (superactivated carbons AX-21 and Maxsorb, TC, and CNTs). The kinetics of uptake were studied by increasing the pressure in steps and following the fractional completion vs. time during each step. Figure 6 shows the adsorption kinetics of hydrogen on graphene and other carbons at $\sim 6 \mathrm{MPa}$ final pressure and $298 \mathrm{~K}$. It is seen that the adsorption rates on graphene were clearly slower than on all other carbons. For all other carbons, the adsorption was completed within $10 \mathrm{~min}$, whereas for graphene the completion for total uptake took $\sim 25 \mathrm{~min}$. This indicates a unique hydrogen uptake process that occurs on graphene. A detailed comparison of adsorption kinetics on graphene and AX-21 carbon at various pressures was carried out further. As shown in Figure 7, the adsorption on AX-21 at all pressures was completed within $10 \mathrm{~min}$. For graphene, the completion time ranged from 12 to more than $30 \mathrm{~min}$, and the kinetics became slower with the increase in pressure. The difference between graphene and AX-21 is more clearly shown by comparing their fractional uptake completion during individual pressure steps (Figure 8). Within $0.5 \mathrm{~min}$, over $90 \%$ completion was accomplished on AX-21, whereas the remaining $10 \%$ was completed in less than $10 \mathrm{~min}$. This can be understood because the fast adsorption of $\mathrm{H}_{2}$ on $\mathrm{AX}-21$ was via van der Waals interactions. In $0.5 \mathrm{~min}$, the adsorption on graphene had completion fractions of $76 \%$ at $2.0 \mathrm{MPa}, 53 \%$ at $6.3 \mathrm{MPa}$, and $33 \%$ at $7.9 \mathrm{MPa}$. The slower adsorption rates on graphene compared with AX-21 and other carbons indicate that a chemical process may be involved in addition to physical adsorption.

Previous theoretical studies showed that the edge sites or structural vacancies on graphene could dissociate $\mathrm{H}_{2}$ into $\mathrm{H}$ atoms. ${ }^{34-37}$ Despite their activities, free edge sites (zigzag and armchair sites) and their joint corner sites could be stable enough to remain free (i.e., not hydrogenated) at ambient temperature. $^{38,39}$ To gain further insight into the activities of graphene, the $\mathrm{H}_{2} / \mathrm{D}_{2} / \mathrm{HD}$ isotope equilibrium reaction was used. The reaction rate for graphene was measured using a slightly modified procedure proposed by Ishikawa et al (See experiment section). ${ }^{32}$ In this new procedure, a mixture of $\mathrm{H}_{2}$ and $\mathrm{D}_{2}$ (1:1 ratio) was allowed to mix uniformly $(2 \mathrm{~h})$ at $\mathrm{RT}$ in a stainless steel dosing cell before being exposed to the sample. The gas in the dosing cell was then introduced to the sample cell after which the two cells were then isolated. The gas in the sample cell was allowed to react with the sample for a specific amount of time (time at RT) before the sample cell was quenched in liquid nitrogen and remained there. Five minutes from the moment the sample cell was submersed in liquid nitrogen, the gas was sampled via a molecular leak valve and analyzed using a MS. Graphene $(20 \mathrm{mg}$ ) was subjected to this treatment and compared to the results obtained on AX-21 (20 mg), 6 wt \% Pt-doped AX-21 (20 $\mathrm{mg}$ ), and the blank cell. The Pt-doped AX-21 is known to have catalytic activities and adsorbs hydrogen via a hydrogen dissociation/spillover process. ${ }^{40}$ The reaction $\mathrm{H}_{2}+\mathrm{D}_{2} \rightarrow$ 2HD $\left(K_{\text {eq }} \sim 3.5\right)$ was measured as a function of completion vs. time at RT, and a correction was added to the time at RT to account for the cooling process. In Figure 9, a first-order rate is shown for both the graphene and Pt-doped AX-21
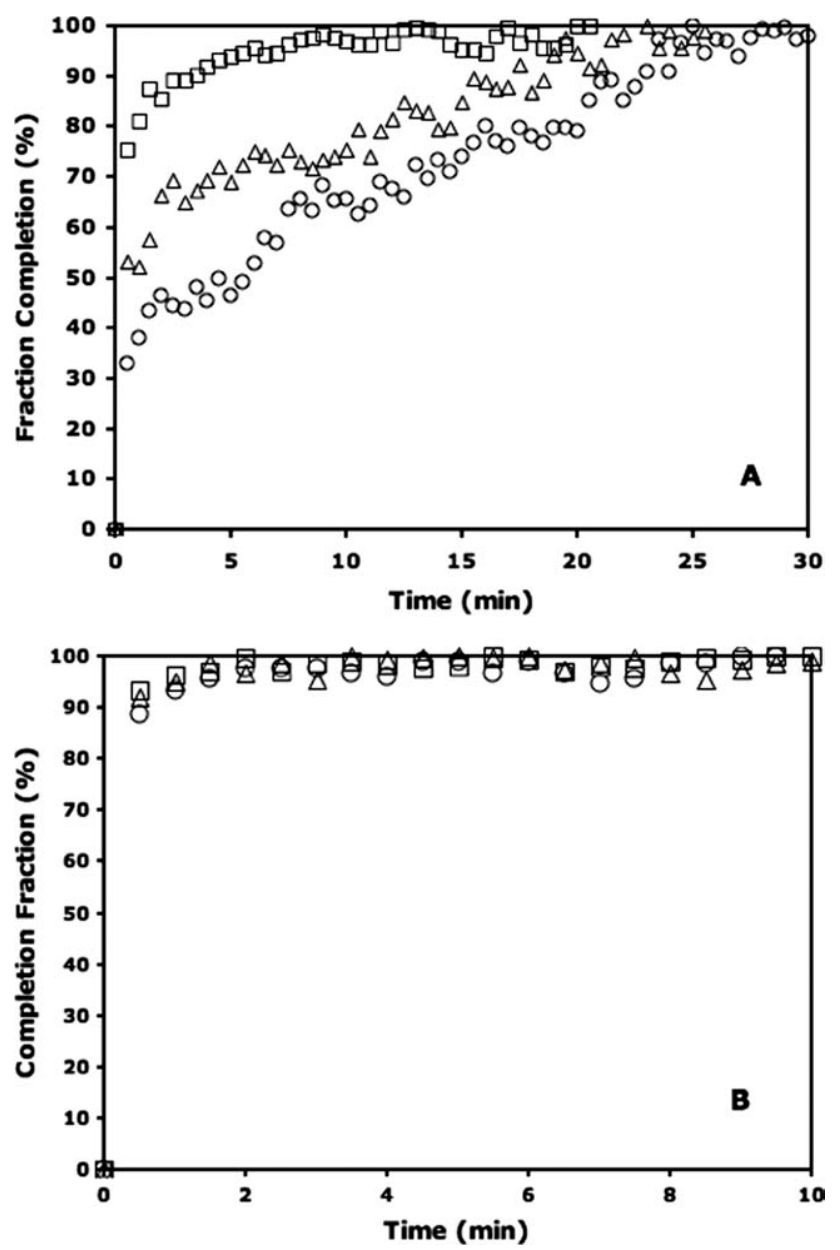

Figure 7. Adsorption fraction at $298 \mathrm{~K}$ on graphene (A) and $A X-21$ carbon (B) during each pressure ramp step at final pressures of: $\sim 2 \mathrm{MPa}(\square)$, 6.2 MPa $(\Delta)$, and 7.9 MPa (○). 

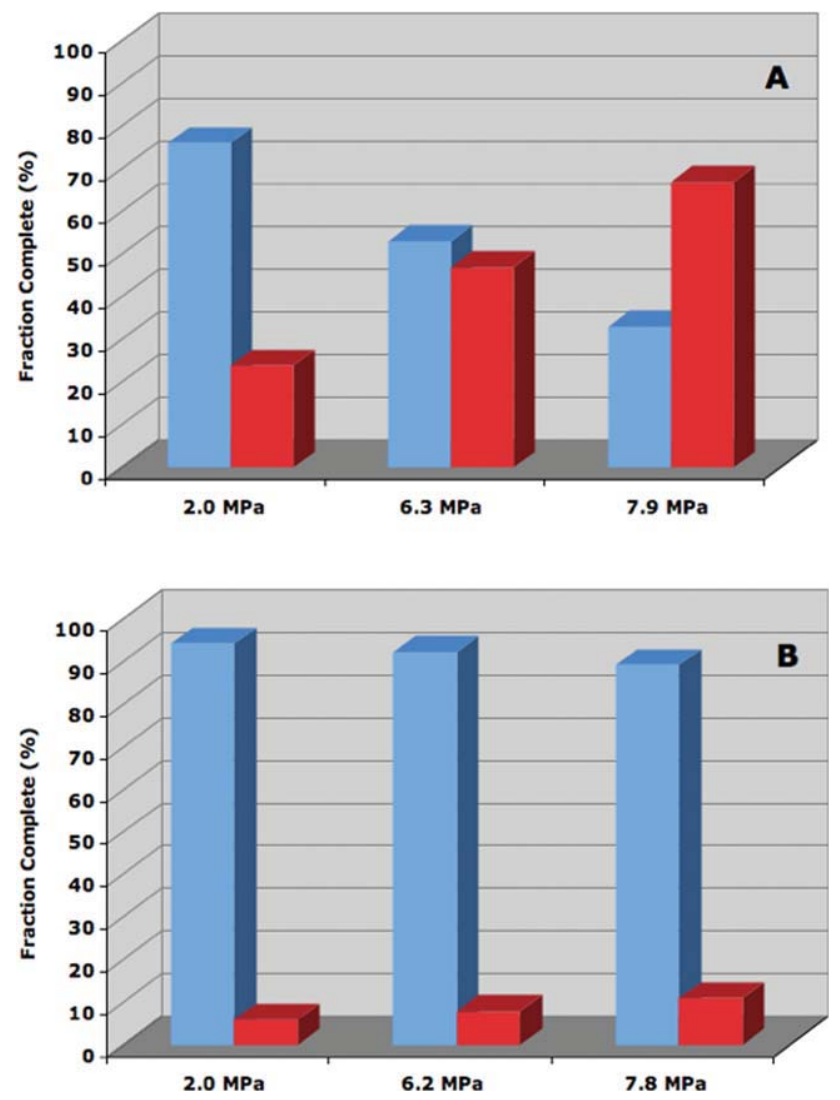

Figure 8. Fraction completion for adsorption on graphene (A) and AX-21 carbon (B) during each pressure ramp step at final pressures of 2 , $\sim 6.2$, and $\sim 7.9 \mathrm{MPa}$.

Blue (left) column: Fraction completed within $0.5 \mathrm{~min}$; red (right) column: fraction completed after $0.5 \mathrm{~min}$. [Color figure can be viewed in the online issue, which is available at wileyonlinelibrary.com.]

dissociation rates. Given the highly increased dissociation rates compared with $\mathrm{AX}-21$ and the blank cell, it is clear that graphene and Pt-doped carbon have similar hydrogen dissociation capabilities. It is also clear that there is an additional hydrogen dissociation mechanism for graphene that was not observed by Ishikawa et al. for graphite. ${ }^{32}$ To our knowledge, this is the first time this highly increased catalytic activity for graphene (when compared with all other carbons) has been observed experimentally.

To gain insight into possible binding sites and the relation between adsorption and hydrogen dissociation, we also measured TPD spectra for graphene (as explained in Experimental section.). The TPD spectrum continues from the end of the $\mathrm{H}_{2} / \mathrm{D}_{2} / \mathrm{HD}$ reaction and starts by evacuating all gas from the sample while still at liquid nitrogen and heating at a specified rate all while monitoring the evolved gas using the same MS. These spectra were taken after time at RT of $0.5 \mathrm{~min}, 1.5 \mathrm{~min}$, and $2 \mathrm{~h}$. As shown in Figure 10, TPD for time at RT of 2-h adsorption shows a clear peak with isotopic effects above RT (hydrogen comes out in higher concentration than is present in the system). At only $1.5 \mathrm{~min}$ at $\mathrm{RT}$, this peak disappears and a new peak (assumed to be hidden) becomes apparent at lower temperature. At $0.5 \mathrm{~min}$ at RT, only the peaks due to physically adsorbed species seem to be present. Previous work on hydrogen spillover suggests that reverse spillover and surface recombination of $\mathrm{H} / \mathrm{D}$ will be the two probable methods for hydrogen desorption. ${ }^{41}$ We have assigned the peak at higher temperatures to surface recombination due to isotopic effects (i.e., the lightest species are in greatest concentration). A blank TPD and plain AX-21 showed no peaks except the typical rise in hydrogen when approaching the degas temperature (starting around $473 \mathrm{~K}$ ) and the physical adsorbed hydrogen during initial heating for AX-21. TPD for AX-21 is provided (Supporting Information Figure S3).

The recombination and subsequent desorption is inherently measured in the $\mathrm{H}_{2} / \mathrm{D}_{2} / \mathrm{HD}$ experiment showing that the bond formed between these most active graphene dissociation sites and hydrogen is very weak. Further, the reaction rate shown here for dissociation (Figure 9) is faster than the completion rate for hydrogen uptake. This shows that the sites responsible for hydrogen dissociation are not the only sites increasing the hydrogen storage. A degas temperature of $823 \mathrm{~K}$ also shows that effective sites are stable at high temperatures. Theoretical and experimental studies suggest that a functional on the graphene (the zigzag edge) is the most reactive site and would be capable of dissociating hydrogen. ${ }^{36,38}$ This may be able to explain the difference between adsorption and the hydrogen dissociation rates. Other studies suggesting direct dissociation on the basal plane may be able to explain the slow adsorption rates as an alternative to a possible spillover mechanism. ${ }^{42}$ The lack of studies on other functional groups indicate they should not be ruled out, including the possibility of sodium implanted into the carbon lattice or as a salt with carboxylic groups on the edges. However, further experiments are warranted for understanding the hydrogen adsorption sites present on graphene and the effect of oxygen and sodium.

\section{Conclusions}

In summary, hydrogen adsorption properties of graphene have been studied and compared with a diverse collection of

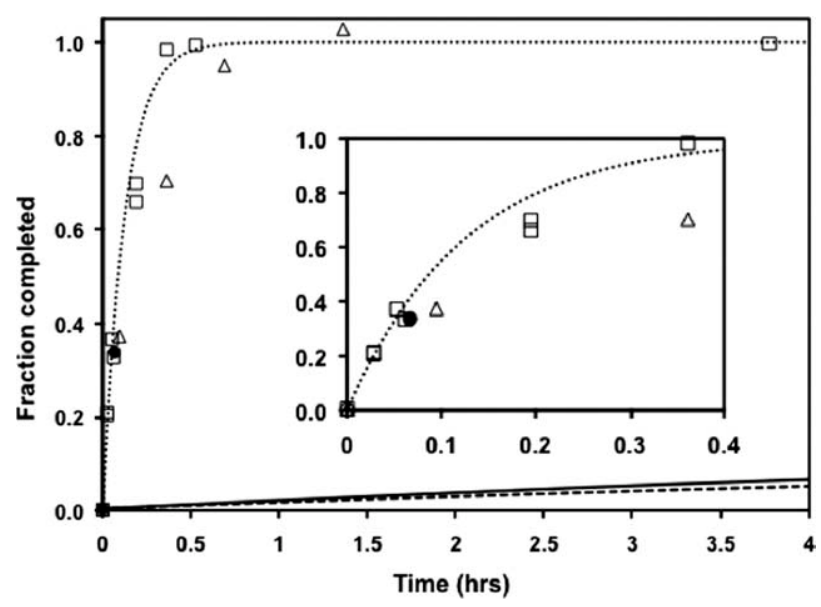

Figure 9. $H_{2}+D_{2} \rightarrow 2 H D$ reaction rates at $298 \mathrm{~K}$.

Graphene ( $\square$ ) (time at RT and extrapolated to account for cooling time), AX-21 (-), graphene after pretreatment at $823 \mathrm{~K}(\circlearrowleft), \mathrm{Pt} / \mathrm{AX}-21(\Delta)$, blank cell $(-)$, and fit assuming reversible first-order reaction rate $(\ldots)$. 


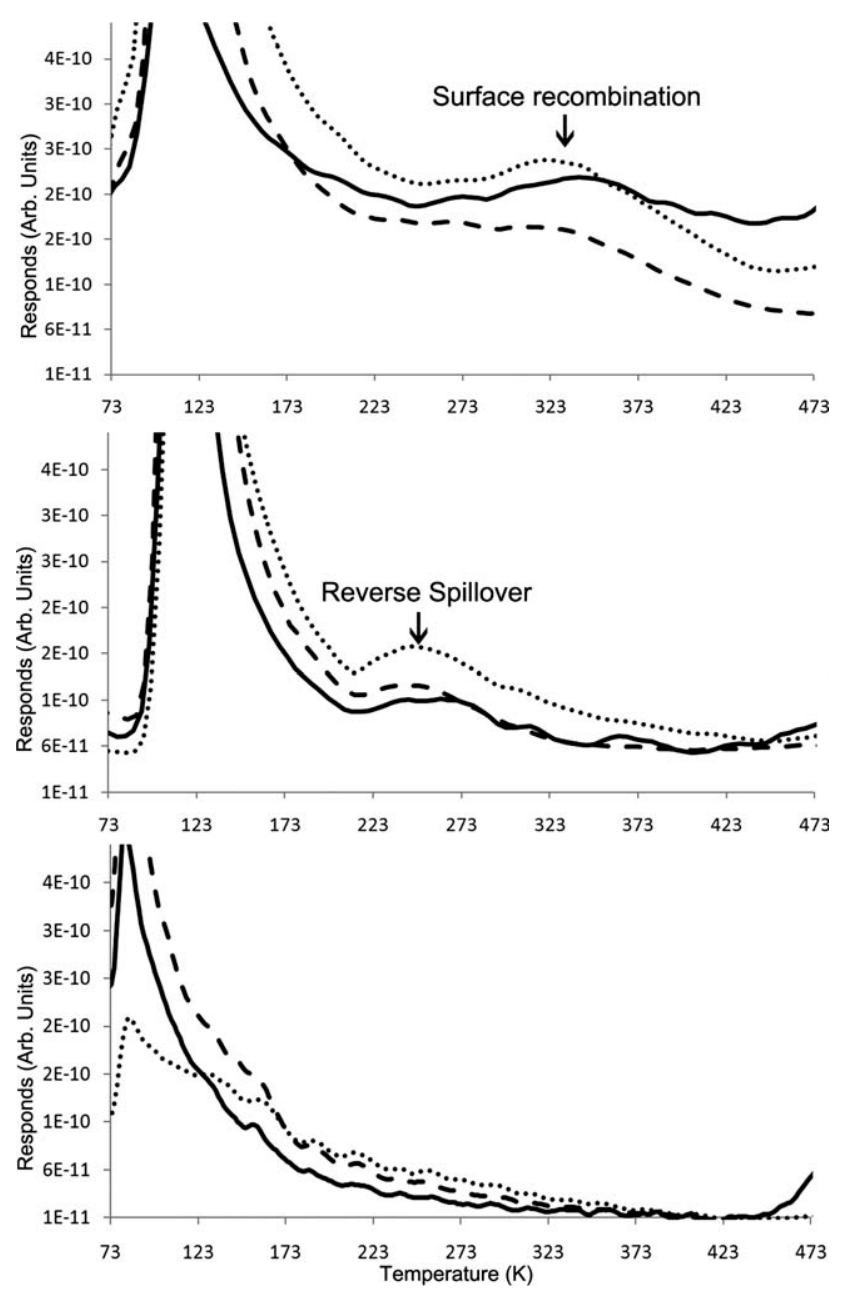

Figure 10. The TPD spectra for graphene are shown for $2 \mathrm{~h}$ (top), $1.5 \mathrm{~min}$ (middle), and $0.5 \mathrm{~min}$ (bottom) exposure time to a $H_{2} / D_{2}$ mix at $298 \mathrm{~K}$ and $1.6 \mathrm{MPa}$.

$\mathrm{H}_{2}(-), \mathrm{D}_{2}(-)$, and $\mathrm{HD}(\ldots)$ are shown for all spectra. Evolution of two different peaks can be seen (one possibly corresponding to reverse spillover and the other possibly to surface recombination of $\mathrm{H}$ atoms). High concentrations of physically adsorbed hydrogen are due to quenching while under high pressure.

carbon materials. Graphene shows an unusually high hydrogen storage capacity and a unique hydrogen adsorption process. The dissociation of hydrogen on graphene has been observed experimentally for the first time. We have also shown that the hydrogen dissociation rate is significantly faster than the adsorption rate. This leads us to conclude that the most active sites for dissociation are not the only sites where the enhanced adsorption occurs. The slow adsorption rates and TPD results show adsorption mechanism differences in graphene compared with activated carbon and demonstrate the unique hydrogen storage capabilities of graphene.

\section{Acknowledgment}

This work was supported by funding from NSF under grant CBET0753008 .

\section{Literature Cited}

1. Novoselov KS, Geim AK, Morozov SV, Jiang D, Zhang Y, Dubonos SV, Grigorieva IV, Firsov AA. Electric field effect in atomically thin carbon films. Science. 2004;306:666-669.

2. Stankovich S, Dikin DA, Dommett GHB, Kohlhaas KM, Zimney EJ, Stach EA, Piner RD, Nguyen ST, Ruoff RS. Graphene-based composite materials. Nature. 2006;442:282-286.

3. Kim KS, Zhao Y, Jang H, Lee SY, Kim JM, Kim KS, Ahn JH, Kim $\mathrm{P}$, Choi JY, Hong BH. Large-scale pattern growth of graphene films for stretchable transparent electrodes. Nature. 2009;457:706-710.

4. Choucair M, Thordarson P, Stride JA. Gram-scale production of graphene based on solvothermal synthesis and sonication. Nat Nanotechnol. 2009;4:30-33.

5. Li XL, Wang XR, Zhang L, Lee SW, Dai HJ. Chemically derived, ultrasmooth graphene nanoribbon semiconductors. Science. 2008; 319:1229-1232.

6. Geim AK, Novoselov KS. The rise of graphene. Nat Mater. 2007;6: 183-191.

7. Zhang Y, Guo L, Wei S, He Y, Xia H, Chen Q, Sun HB, Xiao FS. Direct imprinting of microcircuits on graphene oxides film by femtosecond laser reduction. Nano Today. 2010;5:15-20.

8. Sofo JO, Chaudhari AS, Barber GD. Graphane: a two-dimensional hydrocarbon. Phys Rev B. 2007;75:153401.

9. Dimitrakakis GK, Tylianakis E, Froudakis GE. Pillared graphene: a new 3-D network nanostructure for enhanced hydrogen storage. Nano Lett. 2008;8:3166-3170.

10. Lin Y, Ding F, Yakobson BI. Hydrogen storage by spillover on graphene as a phase nucleation process. Phys Rev B. 2008;78:041402.

11. Xu WC, Takahashia K, Matsuoa Y, Hattoria Y, Kumagaia M, Ishiyamab S, Kanekoc K, Iijima S. Investigation of hydrogen storage capacity of various carbon materials. Int J Hydrogen Energy. 2007; 32:2504-2512.

12. Miller MA, Wang CY, Merrill GN. Experimental and theoretical investigation into hydrogen storage via spillover in IRMOF-8. J Phys Chem C. 2009;113:3222-3231.

13. Zhao D, Yuan D, Zhou HC. The current status of hydrogen storage in metal-organic frameworks. Energy Environ Sci. 2008;1:222-235.

14. Wang L, Yang RT. New sorbents for hydrogen storage by hydrogen spillover-a review. Energy Environ Sci. 2008;1:268-279.

15. Frost H, Duren T, Snurr RQ. Effects of surface area, free volume, and heat of adsorption on hydrogen uptake in metal-organic frameworks. J Phys Chem B. 2006;110:9565-9570.

16. Frost H, Snurr RQ. Design requirements for metal-organic frameworks as hydrogen storage materials. J Phys Chem C. 2007;111:18794-18803.

17. Chung TCM, Jeong Y, Che Q, Kleinhammes A, Wu Y. Synthesis of microporous boron-substituted carbon $(\mathrm{B} / \mathrm{C})$ materials using polymeric precursors for hydrogen physisorption. J Am Chem Soc. 2008; 130:6668-6669.

18. Ma LP, Wu ZS, Li J, Wu ED, Ren WC, Cheng HM. Hydrogen adsorption behavior of graphene above critical temperature. Int $J$ Hydrogen Energy. 2009;349:2329-2332.

19. Ghosh A, Subrahmanyam KS, Krishna KS, Datta S, Govindaraj A, Pati SK, Rao CNR. Uptake of $\mathrm{H}_{2}$ and $\mathrm{CO}_{2}$ by graphene. $J$ Phys Chem C. 2008;112:15704-15707.

20. Srinivas G, Zhu Y, Piner R, Skipper N, Ellerby M, Ruoff R. Synthesis of graphene-like nanosheets and their hydrogen adsorption capacity. Carbon. 2010;48:630-635.

21. Elias DC, Nair RR, Mohiuddin TMG, Morozov SV, Blake P, Halsall MP, Ferrari AC, Boukhvalov DW, Katsnelson MI, Geim AK, Novoselov KS. Control of graphene's properties by reversible hydrogenation: evidence for graphane. Science. 2009;323:610-613.

22. Balog R, Jorgensen B, Wells J, Lagsgaard E, Hofmann P, Besenbacher F, Hornekar L. Atomic hydrogen adsorbate structures on graphene. J Am Chem Soc. 2009;131:8744-8745.

23. Jun S, Joo SH, Ryoo R, Kruk M, Jaroniec M, Liu Z, Ohsuna T, Terasaki O. Synthesis of new, nanoporous carbon with hexagonally ordered mesostructure. J Am Chem Soc. 2000;122:10712-10713.

24. Ma Z, Kyotani T, Liu Z, Terasaki O, Tomita A. Very high surface area microporous carbon with a three-dimensional nano-array structure: synthesis and its molecular structure. Chem Mater. 2001;13:4413-4415.

25. Lachawiec J, Yang RT. Isotope tracer study of hydrogen spillover on carbon-based adsorbents for hydrogen storage. Langmuir. 2008; 24:6159-6165. 
26. Gaslain FOM, Parmentier J, Valtchev VP, Patarin J. First zeolite carbon replica with a well resolved X-ray diffraction pattern. Chem Commun. 2006;991-993.

27. Wang L, Yang RT. Hydrogen storage properties of carbons doped with ruthenium, platinum, and nickel nanoparticles. $J$ Phys Chem C. 2008;112:12486-12494.

28. Chae H, Siberio-Perez DY, Kim J, Go Y, Eddaoudi M, Matzger A, O'Keeffe M, Yaghi OM. A route to high surface area, porosity and inclusion of large molecules in crystals. Nature. 2004;427: 523-527.

29. Haas MK, Zielinski JM, Dantsin G, Coe CG, Pez GP, Cooper AC. Tailoring singlewalled carbon nanotubes for hydrogen storage. J Mater Res. 2005;20:3214-3223.

30. Li Y, Yang RT. Hydrogen storage on platinum nanoparticles doped on superactivated carbon. J Phys Chem C. 2007;111:11086-11094.

31. Lachawiec AJ, DiRamondo TR, Yang RT. A robust volumetric apparatus and method for measuring high pressure hydrogen storage properties of nanostructured materials. Rev Sci Instrum. 2008;79: 063906-063917.

32. Ishikawa Y, Austin LG, Brown DE, Walker PL Jr. Ortho-parahydrogen conversion and hydrogen-deuterium equilibration over carbon surfaces. In: Walker PL, Thrower PA, editors. Chemistry and Physics of Carbon. New York: Marcel Dekker, 1975:39-108.

33. Bénard P, Chahine R. Determination of the adsorption isotherms of hydrogen on activated carbons above the critical temperature of the adsorbate over wide temperature and pressure ranges. Langmuir. 2001;17:1950-1955.
34. Arboleda NB, Kasai H, Nakanishi H, Dino WA, Sugimot T. Scattering and dissociative adsorption of $\mathrm{H}_{2}$ on the armchair and zigzag edges of graphite. J Appl Phys. 2004;96:6331-6336.

35. Sha X, Jackson B. The location of adsorbed hydrogen in graphite nanostructures. J Am Chem Soc. 2004;126:13095-13099.

36. Jiang DE, Sumpter BG, Dai S. Unique chemical reactivity of a graphene nanoribbon's zigzag edge. J Chem Phys. 2007;126:134701-134706.

37. Lei Y, Shevlin SA, Zhu W, Guo ZX. Hydrogen-induced magnetization and tunable hydrogen storage in graphitic structures. Phys Rev B. 2008;77:134114.

38. Radovic LR, Bockrath B. On the chemical nature of graphene edges: origin of stability and potential for magnetism in carbon materials. J Am Chem Soc. 2005; 127:5917-5927.

39. Radovic LR. Active sites in graphene and the mechanism of $\mathrm{CO}_{2}$ formation in carbon oxidation. J Am Chem Soc. 2009;131:17166-17175.

40. Stuckert NR, Wang L, Yang RT. Characteristics of hydrogen storage by spillover on Pt-doped carbon and catalyst-bridged metal organic framework. Langmuir. 2010;26:11963-11971.

41. Conner WC Jr, Falconer JL. Spillover in heterogeneous catalysis. Chem Rev. 1995;95:759-788.

42. McKay H, Wales DJ, Jenkins SJ, Verges JA, de Andres PL. Hydrogen on graphene under stress: molecular dissociation and gap opening. Phys Rev B. 2010;81:075425.

Manuscript received Aug. 21, 2010, and revision received Oct. 6, 2010. 